\title{
Prevalence and Associated Risk Factors of Iron Deficiency Anemia Among School Teenagers in Mbouda, Western Cameroon: A Cross Sectional Study
}

\author{
O. Tadzong Mamokem, M. M. Kana Sop, W. J. Takougoum Marbou and B. P. Telefo
}

\section{ABSTRACT}

Teenagers are a particularly vulnerable age group to Iron Deficiency Anemia (IDA). This study aimed to determine the prevalence and associated risks factors of IDA among apparently healthy school teenagers in Mbouda, West-Cameroon. Blood samples, up to 778 were randomly collected from adolescents aged 10-19 years of four schools in Mbouda. For this crosssectional study, participants collaborated to fill a questionnaire with us on socio-economic and demographic status. The methods of 24 hours recall, and dietary history were used to determine the dietary habits, the type of food and the consumed meal frequencies during a day. Appropriate indicators including hemoglobin and hematocrit, serum iron, ferritin, transferrin, and total iron binding capacity, transferrin saturation were determined using standard methods. Our findings showed that the prevalence of IDA was $82.4 \%$ and $17.64 \%$ in participants aged $13-19$ years and 10-12 years respectively. High significant difference in the mean values of Serum Iron $(p=0.001)$, Serum ferritin $(p<0.001)$, TIBC $(p<0.001)$, CST $(0.001)$ and Hemoglobin $(p<0.001, C I=2)$ were observed in participants without IDA compared to those with IDA. The sociodemographic risk factors of IDA in school adolescents were sex $[P=0.001, O R=0.39(0.22-$ 0.69) $]$, residence areas $[P=0.001, O R=3.30(1.55-7.02)]$ and school sites $[P$ $=0.002]$. Consumption of vegetable [OR: $0.30(0.17-0.54)]$, fruits, [OR: 0.26 $(0.12-0.52)]$ and fats [OR: $0.33(0.12-0.91)]$ significantly decreased the risk of IDA $(p<0.05)$, whereas the consumption of legumes [OR: 2.60 (1.574.32)] significantly increased the risk of IDA. This study suggested that IDA could be prevented by providing proper knowledge on the healthful diet including fats animal food sources, fruit and vegetables, improved lifestyle, and on the harmful effects of IDA to the teenager's productivity.

Keywords: Blood parameters, Cameroon, dietary diversity, iron deficiency anemia, school teenagers.
Submitted : December 25, 2021

Published : January 28, 2022

ISSN: $2593-8339$

DOI: $10.24018 /$ ejmed.2022.4.1.1178

\section{O. Tadzong Mamokem}

Department of Biochemistry, Faculty of Science, University of Dschang, Cameroon.

(e-mail: odtido@yahoo.fr)

M. M. Kana Sop

Department of Biochemistry, University of Douala, Douala, Cameroon.

(e-mail: kanamod@yahoo.com)

W. J. Takougoum Marbou

Department of Biochemistry, Faculty of Science, University of Dschang, Cameroon.

(e-mail: marboutakougoum@yahoo.fr) B. P. Telefo*

Department of Biochemistry, Faculty of Science, University of Dschang, Cameroon.

(e-mail: bphelix@yahoo.co.uk)

*Corresponding Author

\section{INTRODUCTION}

Anemia is a major public health problem worldwide with prevalence of $43 \%$ in developing countries and $9 \%$ in developed nations [1]. The global prevalence of anemia among school-aged children is $25.4 \%$ [2] and $27 \%$ among adolescents in developing countries [3]. The etiology of anemia is multifactorial: inherited (Thalassemia and sickle cell), infections (malaria), autoimmune (hemolytic anemia), socioeconomic, demographic, and nutritional (iron, folic acid, and Vitamin B12 deficiencies), malabsorption (achlorhydria), chronic diseases (cancer) [4]. One in 2 pregnant women and around 40 percent of preschools children are reported to be anemic. Two billion people that are probably more than $30 \%$ of the world's population suffer from anemia, mainly due to iron deficiency [5], especially in developing countries [6] like Cameroon. Iron deficiency anemia is a global nutritional problem that mainly affects infants, children, adolescents and women of childbearing age [7]-[9].

Iron is an essential part of the hemoglobin, myoglobin and various enzymes. Its deficiency leads mainly to anemia. Iron is recognized as an essential nutrient that is required for oxygen transport, energy production and metabolism of many bioactive compounds in all living organisms [10]. The health impact of iron deficiency is very significant in adults, children and adolescents. Adolescents are at increased risk of iron deficiency linked to period of rapid growth and developmental process of adolescence, which cause higher requirement on iron [11]. This explains their recommended nutritional intakes for iron of $10 \mathrm{mg}$ /daily for 10 to 12 years in both sexes, $13 \mathrm{mg}$ for adolescents and $16 \mathrm{mg} /$ daily for adolescents 13-19 years [11]. Usually, deficiency of iron gradually develops and does not have clinically apparent 
symptoms until anemia becomes severe [12].

The etiology of IDA during puberty might be due to increased iron demand/loss or decreased iron intake, chronic blood loss, iron malabsorption (celiac disease), pregnancy, or parasitic infection (helminthiasis), which may lead to decreased intellectual and work performance and learning difficulties [13]. Poor activity, mental, and educational performances among children that have strong relations with IDA may also continue into adulthood and cause low work efficiency, which has effects on the economic productivity [4].

In Cameroon, the Demographic Health Survey of 2018 found that iron deficiency affected $68 \%$ of children under five [14]. Kana sop et al. indicated a prevalence of iron deficiency of $51.41 \%$ in children aged 0 to 24 months in six health centers in the Bangang Rural Community in western Cameroon [15]. Forty-one-point seven percent $41.7 \%$ of adolescent girls 15 to 19 years are anemic in Cameroon. Iron deficiency is one of the main causes of anemia which has serious consequences for both women's and children's health in Cameroon [16]. Despite the multiple consequences of anemia on the health of adolescents, research relating to IDA anemia in school adolescents 10-19 years is rare in Cameroon. So far, previous studies were focused on children under five and women of childbearing age or pregnant women. Consequently, the current study aims to assess the prevalence and risk factors of iron deficiency anemia among apparently healthy school adolescents 10-19 years in Mbouda, Western Cameroon.

\section{Methodology}

\section{A. Study Design}

This was a cross sectional study conducted from September 2018 to December 2020, in order to assess the prevalence and the risk factors of iron deficiency anemia among apparently healthy school adolescents in Mbouda, Western Region of Cameroon.

\section{B. Study Subjects}

The present study includes 778 school adolescents aged 1019 years randomly selected from four schools in Mbouda. Also, 778 blood samples were collected.

\section{Data and Samples Collections}

Data were collected using structured questionnaire. The questionnaire had sociodemographic characteristics. Girls' menstruation was assessed. The menstruation duration period per week was stratified as $<5$ days and $\geq 5$ days.

To determine dietary habits, the methods of 24-hour recall method and the meal consumption frequency per day were used. Twelve food groups were obtained from various meals according to FAO/INFOODS Food Composition Table for Western Africa (WAFCT) criteria [17]. Dietary Diversity Score (DDS) was calculated by summing the number of different food groups irrespective of the amount consumed over the past 24-hours period. It was classified as poor, medium, and high DDS if the participants consume less than six, six or more than six food items in the last 24 hours respectively. Moreover, the frequency of consumption of meals during the 24 hours was determined as follows: 1 meal $/$ day $=$ weak $(\mathrm{W}) ; 2$ meals $/$ day $=$ Fairly $\operatorname{good}(\mathrm{FG}) ; 3$ meals/day $=$ Good $(\mathrm{G})$; more than 3 meals/day = Very Good frequency $(\mathrm{VG})$.

\section{Biochemical Parameters}

Five $\mathrm{ml}(05 \mathrm{ml})$ of venous blood were taken from each student to measure Hemoglobin (Hb), Serum Iron (SI), serum ferritin (SF), and Transferrin. The hemoglobin assay was performed by optical reflection technic using a Hemostat GOLD hemoglobin meter (Hemoglobin Screening Meter, Apex Bio, and Taiwan). The biochemical parameters were assayed by photometry on Cobas C311 from ROCHE Diagnostic. Serum Iron was assessed by enzymatic colorimetric based on FerroZine without deproteinization (KIT for iron assay on Cobas C311, ROCHE Diagnostic). Transferrin and Ferritin were determined by immuno-turbid metric assay (KIT for assaying transferrin and ferritin on Cobas C311, ROCHE Diagnostic). Transferrin Saturation coefficient (TSC) and Total Iron Binding Capacity by transferrin (TIBC) were determined by calculation from transferrin according to WHO and CDC, 2004 [18]. Two Higher diploma nurses were recruited to confirm the physical health status of each participant and three higher diploma laboratory technicians for data collection. The adolescents were declared anemic or not according to World Health Organization criteria [19]. IDA was equally defined according to World Health Organization criteria [20].

\section{E. Ethical Approval}

The National ethics committee of Cameroon (Ref $\mathrm{n}^{\circ}$ 2018/08/1086/CE/CNERSH) approved experimental procedures and protocols used in this study. In addition, authorizations from the Sub Divisional Delegate of Secondary Education of Bamboutos and that of the head of district health Centre of Mbouda were obtained. Informed, signed consent and assent to participate in the study were obtained from all parents' participants.

\section{F. Statistical Analysis}

Data were analyzed using SPSS version 18.0 statistical software. Odds ratio (OR) with their 95\% confidence level (CI) were calculated. Descriptive statistics of continuous and discontinuous variables were expressed as Mean \pm Standard Deviation $( \pm \mathrm{SD})$ and Percentage and compare with chisquare test and student t-test respectively. $\mathrm{p}<0.05$ was considered as statistically significant.

\section{RESULTS}

\section{A. Prevalence of Iron Deficiency Anemia among Students}

A total number of 778 blood samples were analyzed for iron deficiency with anemia screening. The statistics of the number of participants collected per school were as follows: Bilingual High School Mbouda (327), Technical High School Mbouda (226) in urban area, Technical High School Bamendjo (133) and High School Bamenkombo (92) in rural area. $17.64 \%$ of adolescents aged $10-12$ years $(n=12)$ were anemic, compared to $82.4 \%$ for those aged 13-19 years $(n=56)$ which revealed that the prevalence of IDA increased with adolescents' age. According to age and gender (Table I), females in the 10-12 age range had $18 \%$ prevalence against $16.67 \%$ for males. Contrary, the females in the range 13-19 age range had $82 \%$ prevalence against $83.33 \%$ for males. Therefore, IDA increased with age in both sexes as indicated 
in Table I. Considering the variable related to residence area, we observed that in rural area, IDA is less represented in female $10.0 \%(n=5)$ than in male $16.67 \%(n=3)(p=0.724)$, contrary in urban area, IDA is more represented in female
$90.0 \%(n=45)$ than in male $83.33 \%(n=15)(p=0.001)$. According to the site or school, high prevalence of IDA was observed for females in TH Mbouda $48.0 \%(n=24)$ compared to male $27.77 \%(n=5)(p=0.001)$.

TABLE I: PREVALENCE OF IRON DEFICIENCY ANEMIA ACCORDING TO AGE AND GENDER

\begin{tabular}{|c|c|c|c|c|c|c|c|c|c|c|}
\hline \multirow{2}{*}{\multicolumn{2}{|c|}{ Parameters }} & \multicolumn{4}{|c|}{$\begin{array}{l}\text { Participants without Iron Deficiency Anemia } \\
\qquad(\mathrm{n}=710)\end{array}$} & \multicolumn{4}{|c|}{$\begin{array}{l}\text { Participants with Iron Deficiency Anemia } \\
\qquad(\mathrm{n}=68)\end{array}$} & \multirow[b]{3}{*}{ P-value } \\
\hline & & \multicolumn{2}{|c|}{ Male $(n=340)$} & \multicolumn{2}{|c|}{ Female $(\mathrm{n}=370)$} & \multicolumn{2}{|c|}{ Male $(\mathrm{n}=18)$} & \multicolumn{2}{|c|}{ Female $(\mathrm{n}=50)$} & \\
\hline & & $\mathrm{N}$ & $(\%)$ & $\mathrm{N}$ & $(\%)$ & $\mathrm{N}$ & $(\%)$ & $\mathrm{N}$ & $(\%)$ & \\
\hline \multirow[t]{2}{*}{ Age by year } & $10-12$ & 68 & 20.0 & 49 & 13.24 & 3 & 16.67 & 9 & 18.0 & \multirow{2}{*}{0.804} \\
\hline & $13-19$ & 272 & 80.0 & 321 & 86.76 & 15 & 83.33 & 41 & 82.0 & \\
\hline \multirow{2}{*}{ Residence Area } & Rural & 104 & 30.6 & 113 & 30.6 & 3 & 16.67 & 5 & 10.0 & \multirow{2}{*}{$0.001 *$} \\
\hline & Urban & 236 & 69.4 & 257 & 69.4 & 15 & 83.33 & 45 & 90.0 & \\
\hline \multirow{3}{*}{$\begin{array}{c}\text { Level of } \\
\text { knowledge about } \\
\text { iron deficiency }\end{array}$} & Good & 65 & 19.12 & 79 & 21.35 & 4 & 22.22 & 10 & 20.0 & \multirow{3}{*}{0.338} \\
\hline & Poor knowledge & 255 & 75.0 & 271 & 72.24 & 14 & 77.78 & 39 & 78.0 & \\
\hline & Very good & 20 & 5.88 & 20 & 6.41 & 00 & 0.0 & 1 & 2.0 & \\
\hline \multirow{4}{*}{ Site(school) } & "HS Bamenkombo & 34 & 10.0 & 58 & 177.03 & 00 & 0.0 & 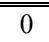 & 0.0 & \multirow{4}{*}{$0.001 *$} \\
\hline & BHS Mbouda & 128 & 37.65 & 168 & 45.41 & 10 & 55.56 & 21 & 42.0 & \\
\hline & THS Bamendjo & 70 & 20.6 & 55 & 14.87 & 3 & 16.67 & 5 & 10.0 & \\
\hline & THS Mbouda & 108 & 31.75 & 89 & 22.69 & 5 & 27.77 & 24 & 48.0 & \\
\hline
\end{tabular}

*Statistically significant at 0.05 significance level; B HS: Bilingual High School, HS: High School, THS: Technical High School. Poor knowledge = Validation of zero to three evaluation criteria; Good knowledge = Validation of at least four evaluation criteria; Very good knowledge $=$ Validation of more than four evaluation criteria. (TB). $\mathrm{N}=778$.

Table II below shows the means of biochemical parameters of iron deficiency with anemia according to age and gender. The average hemoglobin levels for IDA for male and female adolescents were respectively $11.61 \pm 0.67 \mathrm{~g} / \mathrm{dL}$ and $11.22 \pm 0.70 \mathrm{~g} / \mathrm{dL}$ with high statistically significant differences $(\mathrm{p}<0.001)$, compared to non-anemic male $(14.51 \pm 1.71 \mathrm{~g} / \mathrm{dl})$ and non-anemic female adolescents $(13.82 \pm 1.37 \mathrm{~g} / \mathrm{dl})$. Similarly, the mean of SF, SI, and TIBC for IDA male and female adolescents had high significantly level compared to non-anemic male and female adolescents' groups $(\mathrm{p}<0.001)$ (Table II). Using the independent sample $\mathrm{T}$ test and the assumption of non-equal variances, the analysis below indicates that there was a high significant difference in the mean values of Serum Iron $(p=0.001)$, Serum ferritin $(p<0.001)$, TIBC $(p<0.001)$, CST $(0.001)$ and Hemoglobin $(\mathrm{p}<0.001, \mathrm{CI}=2)$ when compared to study participants with or without IDA (Table II).

TABLE II: LEVELS OF BIOCHEMICAL PARAMETERS OF IDA ACCORDING TO AGE AND GENDER

\begin{tabular}{|c|c|c|c|c|c|}
\hline \multirow{3}{*}{ Parameters } & \multicolumn{2}{|c|}{ Participants without Iron Deficiency anaemia } & \multicolumn{2}{|c|}{ Participants with Iron Deficiency anemia } & \multirow[b]{3}{*}{ P-value } \\
\hline & Male & Female & Male & Female & \\
\hline & Mean & Mean & Mean & Mean & \\
\hline Serum Iron (mg/l) & $0.71 \pm 0.32$ & $0.67 \pm 0.38$ & $0.30 \pm 0.14$ & $0.30 \pm 0.16$ & $0.001^{*}$ \\
\hline Serum Ferritin $(\mu \mathrm{g} / 1)$ & $72.58 \pm 42.04$ & $58.84 \pm 36.46$ & $43.86 \pm 36.97$ & $24.25 \pm 17.48$ & $0.001 *$ \\
\hline $\mathrm{TIBC}(\mathrm{mg} / \mathrm{l})$ & $4.51 \pm 0.95$ & $4.82 \pm 1.12$ & $4.44 \pm 0.72$ & $4.89 \pm 0.77$ & $<0.001^{*}$ \\
\hline TSC & $0.16 \pm 0.07$ & $0.14 \pm 0.080$ & $0.07 \pm 0.03$ & $0.04 \pm 0.03$ & $0.001 *$ \\
\hline Transferrin(g/l) & $3.24 \pm 0.68$ & $3.64 \pm 0.80$ & $3.19 \pm 0.52$ & $3.51 \pm 0.55$ & $0.001 *$ \\
\hline Hemoglobin g/dl & $14.51 \pm 1.71$ & $13.82 \pm 1.37$ & $11.61 \pm 0.67$ & $11.22 \pm 0.70$ & $<0.001^{*}$ \\
\hline
\end{tabular}

*-Statistically significant at 0.05 significance level. TIBC: total iron binding capacity; TSC: transferrin saturation coefficient.

The levels of biochemical parameters of IDA according to age and gender are presented in Fig. 1. It illustrates that, out of 356 male participants, $26.7 \%$ had hemoglobin levels in the range of $13-15 \mathrm{~g} / \mathrm{dL}, 9.9 \%$ in the range of $10-12 \mathrm{~g} / \mathrm{dL}, 0.3$ $\%$ in the range of $7-9 \mathrm{~g} / \mathrm{dL}$, and $9.0 \%$ in the range of $16-18$ $\mathrm{g} / \mathrm{dL}$. However, $33.9 \%$ of female participants had hemoglobin range of $13-15 \mathrm{~g} / \mathrm{dL}, 16.4 \%$ in the range $10-12$ $\mathrm{g} / \mathrm{dL}$ and 2.7 in the range $16-18 \mathrm{~g} / \mathrm{dL}$. In addition, it was found that $1.2 \%$ female participants were found with hemoglobin range 7-9 g/dL out of 420 (Fig. 1).

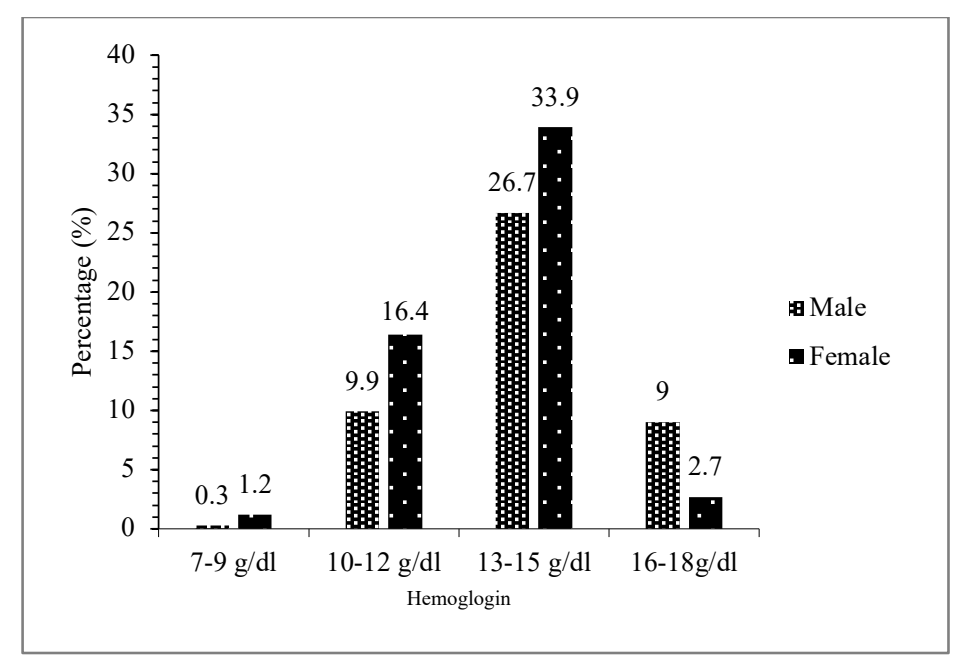

Fig. 1. Comparison of percentage of hemoglobin concentrations for male and female participants. 


\section{B. Sociodemographic Risk Factors Enhancing the Prevalence of IDA in School Adolescents}

Table III below shows multivariate analysis of sociodemographic risk factors of iron IDA among the participants. From all the variables indicated, only sex $[\mathrm{P}=$ $0.001, \mathrm{OR}=0.39(0.22-0.69)]$, residence area $[\mathrm{P}=0.001$, $\mathrm{OR}=3.30(1.55-7.02)]$ and site (school) $[\mathrm{P}=0.002]$ had $\mathrm{a}$ statistically significant association with IDA at 0.05 significant level. All the other factors such as age $(\mathrm{p}=0.864)$, Knowledge on iron deficiency $(\mathrm{p}=0.338)$, profession $(0.37)$ and Family Size $(\mathrm{P}=0.79)$ did not have any significant association with IDA. However, considering the variable related to family size and number of children, we observed that adolescents were more prone to have anemia if they live in households with more than five residents $(6.2 \%)$ than in households with less than five residents or members $(2.6 \%)$. Regarding the level of knowledge about iron deficiency, IDA was more represented in adolescents with poor knowledge $(6.8 \%)$ than those with good $(1.8 \%)$, or those with very good knowledge (2.6\%). Therefore, iron deficiency decreases with the level of knowledge. Concerning father's profession, as we can see from Table III below, IDA was more represented to adolescents whose fathers are traders $(3.1 \%)$, followed by farmers $(2.8 \%)$, civil servants $(1.5 \%)$, others $(0.9 \%)$ and unemployed ( $0.4 \%)$. Coming to the duration of menstruation, adolescent girls whose period of menstruation was equal, or more than five days were more prone to IDA $(6.1 \%)$ than those with less than five days $(2.6 \%)$.

TABLE III: MULTIVARIATE ANALYSIS OF SOCIODEMOGRAPHIC RISK FACTORS OF «IRON DEFICIENCY ANEMIA» AMONG THE PARTICIPANTS

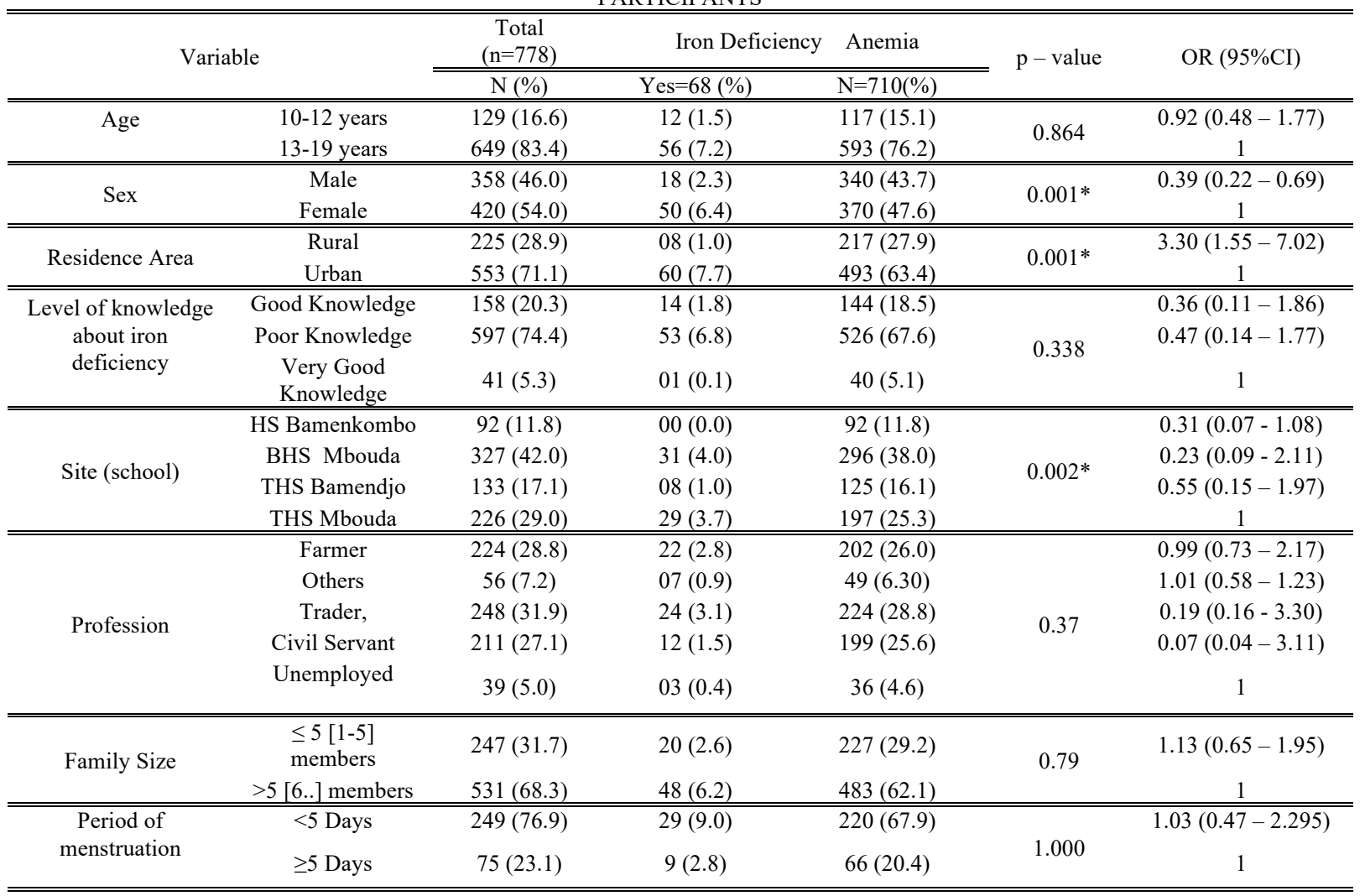

* Significant at 0.05 significance level, BHS: Bilingual High School, HS:High School, THS: Technical High School. Poor knowledge = Validation of zero to three evaluation criteria; Good knowledge $=$ Validation of at least four evaluation criteria; Very good knowledge $=$ Validation of more than four evaluation criteria. (TB).

\section{Dietary Habit Risk Factors Enhancing the Prevalence of Iron Deficiency Anemia among}

Table IV below shows the association between frequency of food groups consumption and the prevalence of IDA: cereals $(p=0.10)$, meat-poultry $(p=0.31)$, eggs $(p=1.00)$, dairy products $(\mathrm{p}=0.064)$, and drinks-sauces-spicescondiments $(\mathrm{p}=0.580)$ did not have any statistically significant association with IDA at 0.05 significance level. The variables that had a statistically significant association with IDA presented by the $\mathrm{P}$ value, OR and (CI) include fish- shrimps $(\mathrm{p}<0.001,0.172 \quad(0.10-0.295), \quad$ vegetables $(\mathrm{p}<0.001), 0.30(0.17-0.54)$, fruits $(\mathrm{p}<0.001)$, nuts and seeds $0.270(0.132-0.554), 0.26(0.12-0.52)$, legumes $(\mathrm{p}<0.001)$, $2.60(1.57-4.32)$ and fats $(\mathrm{p}=0.043), 0.33(0.12-0.91)$.

Therefore, IDA was more prevalent when adolescents consumed fats $(8.1 \%)$, drinks-Sauces- spices-condiments $(6.4 \%)$, cereals $(4.5 \%)$, roots-tubers $(4.2 \%)$, legumes $(4.0$ $\%)$, nuts and seeds $(3.4 \%)$, eggs $(3.0 \%)$ and less prevalent for those who consumed fish-shrimp $(2.7 \%)$, vegetables $(2.1$ $\%)$, meat-poultry $(1.8 \%)$, dairy products $(1.5 \%)$, fruits $(1.2$ $\%)$.

TABLE IV: MULTIVARIATE ANALYSIS OF FOOD GROUPS CONSUMPTION FREQUENCY AS RISK FACTORS OF IRON DEFICIENCY ANEMIA AMONG PARTICIPANTS

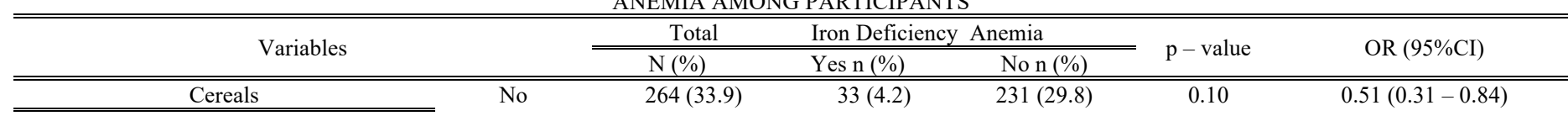


European Journal of Medical and Health Sciences www.ejmed.org

\begin{tabular}{|c|c|c|c|c|c|c|}
\hline & Yes & $514(66.1)$ & $35(4.5)$ & $479(61.6)$ & & 1 \\
\hline \multirow[t]{2}{*}{ Roots-Tubers } & No & $504(64.8)$ & $35(4.5)$ & 469 (60.3) & \multirow{2}{*}{0.023} & $1.84(1.11-3.03)$ \\
\hline & Yes & $274(35.2)$ & $33(4.2)$ & $241(31.0)$ & & 1 \\
\hline \multirow[t]{2}{*}{ Vegetables } & "No & 404 (51.9) & $52(6.7)$ & $352(45.2)$ & \multirow{2}{*}{$<0.001$} & $0.30(0.17-0.54)$ \\
\hline & Yes & $374(48.1)$ & $16(2.1)$ & $358(46.0)$ & & 1 \\
\hline \multirow[t]{2}{*}{ Fruits } & No & $503(64.7)$ & $59(7.6)$ & $444(57.1)$ & \multirow{2}{*}{$<0.001$} & $0.26(0.12-0.52)$ \\
\hline & Yes & $275(35.3)$ & $9(1.2)$ & $266(34.1)$ & & 1 \\
\hline \multirow[t]{2}{*}{ Legumes } & No & $574(73.8)$ & $37(4.8)$ & "537(69.0) & \multirow{2}{*}{$<0.001$} & $2.60(1.57-4.32)$ \\
\hline & Yes & $204(26.2)$ & $31(4.0)$ & $173(22.2)$ & & 1 \\
\hline \multirow[t]{2}{*}{ Meat- Poultry } & No & $573(73.7)$ & $54(6.9)$ & $519(66.7)$ & \multirow{2}{*}{0.314} & $0.70(0.38-1.30)$ \\
\hline & Yes & $205(26.3)$ & $14(1.8)$ & $191(24.6)$ & & 1 \\
\hline \multirow[t]{2}{*}{ Eggs } & No & $510(65.6)$ & $45(5.8)$ & $4665(59.8)$ & \multirow{2}{*}{1.000} & $0.97(0.57-1.64)$ \\
\hline & Yes & $268(34.4)$ & $23(3.0)$ & $245(31.5)$ & & 1 \\
\hline \multirow[t]{2}{*}{ Dairy Products } & No & $564(72.5)$ & $56(7.2)$ & $508(65.3)$ & \multirow{2}{*}{0.064} & $0.54(0.28-1.03)$ \\
\hline & Yes & $214(27.5)$ & $12(1.5)$ & $202(26.0)$ & & 1 \\
\hline \multirow[t]{2}{*}{ Fats } & No & $23(3.0)$ & $5(0.6)$ & $18(2.4)$ & \multirow{2}{*}{0.043} & $0.33(0.12-0.91)$ \\
\hline & Yes & $755(97.0)$ & $63(8.1)$ & $692(88.9)$ & & 1 \\
\hline \multirow{2}{*}{ Drinks-Sauces-Spices -condiments } & No & $234(30.1)$ & $18(2.3)$ & $216(27.9)$ & \multirow{2}{*}{0.580} & $1.22(0.69-2.13)$ \\
\hline & Yes & $544(69.9)$ & $50(6.4)$ & $494(63.5)$ & & 1 \\
\hline \multirow[b]{2}{*}{ Fish-shrimp } & No & $244(31.4)$ & $47(6.0)$ & $197(25.4)$ & \multirow{2}{*}{$<0.001$} & $0.172(0.10-0.295)$ \\
\hline & Yes & $533(68.6)$ & $21(2.7)$ & $512(65.9)$ & & 1 \\
\hline \multirow{2}{*}{ Nuts- Seeds } & No & $513(65.94)$ & $59(11.5)$ & $454(88.5)$ & \multirow{2}{*}{$<0.001$} & $0.270(0.132-0.554)$ \\
\hline & Yes & $265(34.06)$ & $9(3.4)$ & $256(96.6)$ & & 1 \\
\hline
\end{tabular}

Fig. 2 presents in a decreasing order the distribution of food groups according to Dietary Diversity Score (DDS). It emerges from the figure that the ten food groups regularly consumed were fats, drinks-sauces-spices-condiments, fish- shrimp, cereals, vegetables, fruits, nuts-seeds, roots-tubers, eggs and legumes. Therefore, meat-poultry and dairy products were not part of the ten first groups. The prevalence was high in participants consuming fats and drinks-saucesspices-condiments.

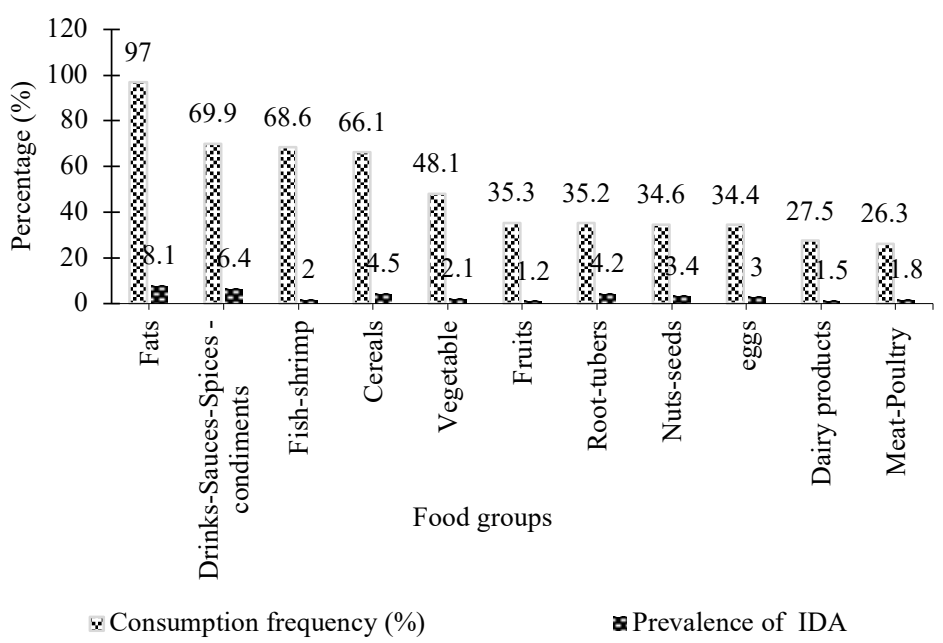

Fig. 2. Consumption frequency of different food groups in a decreasing order and iron deficiency anemia occurrence.

TABLE V: DIETARY DIVERSITY SCORE AND IRON DEFICIENCY ANEMIA AMONG PARTICIPANTS

\begin{tabular}{|c|c|c|c|c|c|c|c|c|c|c|c|}
\hline & \multirow{3}{*}{ Variable } & \multicolumn{9}{|c|}{ Dietary Diversity Score } & \multirow{3}{*}{$\begin{array}{c}\text { Chi- } \\
\text { Square } \\
\text { (P-value) }\end{array}$} \\
\hline & & \multicolumn{4}{|c|}{ Weak } & \multicolumn{2}{|l|}{ Medium } & \multicolumn{2}{|c|}{ Good } & \multirow[b]{2}{*}{10} & \\
\hline & & 2 & 3 & 4 & 5 & 6 & 7 & 8 & 9 & & \\
\hline \multirow{2}{*}{ IDA } & $\begin{array}{c}\text { No } \\
{[710(91.3)]}\end{array}$ & $\begin{array}{c}7 \\
(0.9)\end{array}$ & $\begin{array}{c}35 \\
(4.5)\end{array}$ & $\begin{array}{c}87 \\
(11.2)\end{array}$ & $162(20.8)$ & $\begin{array}{c}197 \\
(25.32)\end{array}$ & $\begin{array}{c}149 \\
(19.1)\end{array}$ & $\begin{array}{c}52 \\
(6.7)\end{array}$ & $\begin{array}{c}19 \\
(2.4)\end{array}$ & $2(0.3)$ & \multirow{2}{*}{$\begin{array}{l}54.525 \\
(<0.001)\end{array}$} \\
\hline & $\begin{array}{c}\text { Yes } \\
{[68(8.7)]}\end{array}$ & 0 & $\begin{array}{c}14 \\
(1.8)\end{array}$ & $21(2.7)$ & $15(1.9)$ & $13(1.7)$ & $3(0.4)$ & $2(0.3)$ & 0 & 0 & \\
\hline Total & 778 & 7 & 49 & 108 & 177 & 210 & 152 & 54 & 19 & 2 & \\
\hline
\end{tabular}

IDA: Iron Deficiency Anemia, Food groups < 6: weak score; Food Groups equal 6: Medium score; Food groups > 6: Good score. 
As we can see from Table $\mathrm{V}$ below, there was a statistically significant association between DDS and IDA $(\mathrm{p}<0.001)$. Less than half $(27 \%)$ of study participants had a medium DDS (equal 6). Adolescents with DDS $\geq 9$ seem to be protected against iron deficiency anemia (0\%). Among participants with weak DDS $(<6)$, those with four food groups 'consumption had the maximum percentage of IDA $(2.7 \%, \mathrm{n}=21)$.

Table VI presents the meal consumption frequency of participants per day. As we can see, meal consumption frequency had a statistically significant association with IDA $(p<0.001)$ at 0.05 significance level. The majority $(70.4 \%)$ of the respondents had meal frequency of $1-2$ times per day with IDA prevalence of $7.1 \%$ out of $8.7 \%$. Adolescent who had good consumption frequency ( 3 meals/day and over) were more protected of iron deficiency anemia (prevalence of 1.7 $\%$ ) than those with weak consumption (prevalence of $3.1 \%$ ). Most of the adolescents with IDA, reported to have Fairly Good Meal Frequency consumption per day out of the $8.7 \%$.

TABLE VI: MULTIVARIATE ANALYSIS OF MEAL CONSUMPTION FREQUENCY AMONG PARTICIPANTS

\begin{tabular}{|c|c|c|c|c|c|c|}
\hline \multirow{2}{*}{\multicolumn{2}{|c|}{ Variable }} & \multirow{2}{*}{$\begin{array}{c}\text { Total } \\
\mathrm{N}(\%) \\
\end{array}$} & \multicolumn{2}{|c|}{ Iron Deficiency Anemia } & \multirow{2}{*}{$\mathrm{p}$ - value } & \multirow{2}{*}{ OR $(95 \% \mathrm{CI})$} \\
\hline & & & Yes & No & & \\
\hline \multirow{3}{*}{ Meal consumption Frequency } & Weak & $105(13.5)$ & $24(3.1)$ & $81(10.4)$ & \multirow{3}{*}{$<0.001$} & $0.97(0.57-1.64)$ \\
\hline & Fairly Good & $443(56.9)$ & $31(4.0)$ & $412(52.9)$ & & $0.76(0.34-1.60)$ \\
\hline & Good & $230(29.6)$ & $13(1.7)$ & $217(27.9)$ & & 1 \\
\hline
\end{tabular}

1 meal/day $=$ weak $(\mathrm{W}) ; 2$ meals/day $=$ Fairly $\operatorname{good}(\mathrm{FG}) ; 3$ meals/day and over $=$ Good $(\mathrm{G})$.

\section{DisCUSSION}

The results of this study revealed that, $17.64 \%$ of adolescents aged 10-12 years were anemic, compared to 82.4 $\%$ for those aged 13-19 years, which revealed that the prevalence of IDA increased with adolescents 'age. In comparison to other findings, these results obtained was slightly similar to what was shown in numerous similar studies that were conducted internationally, nationally as well as regionally, be it in different or the same group of age. For instance, $41.7 \%$ of adolescent girls aged 15 to 19 years, 40 $\%$ women aged 15 to 49 in Cameroon in general, $33.8 \%$ women in west Cameroon, with $50 \%$ were affected by iron deficiency [16]. Internationally, we had $22.5 \%$ of IDA among teenagers in Najran Saudi Arabia in Iran among [10], $30.4 \%$ of IDA among University Students in Hodeida Province Yemen [1]. According to age and gender, females in the $10-12$ age range had $18 \%$ prevalence against $16.67 \%$ for males. Contrarily, the females in the range 13-19 age range had $82 \%$ prevalence against $83.33 \%$ for males. Therefore, IDA increased with age in both sexes as indicated in Table I. This could be explained by the high demand of iron in this very fast growth period of live. In fact, Adolescence is a critical period of growth, reproductive maturation, and developmental transitions which requires increased nutritional intake and therefore makes adolescents more vulnerable to nutritional deficiencies [21]. This finding agrees with that of Abdullah Ahmed et al. reported among University Students in Hodeida Province Yemen where Students aged 20-22 years were found more anemic with prevalence $59.2 \%$ than students aged $17-19$ years $(25.0 \%)$ and $23-25$ years $(15.8 \%)$ [1].

The differences in the prevalence of IDA in these regions could be explained by the fact that the present study was extended to both boys and girls of early and late adolescents of rural and urban communities. Differences in the study areas, cultural variations, sample sizes, lifestyles, socioeconomic, dietary habits and other pathological or genetic factors could be responsible of the observed differences.

As far as the hemoglobin level is concerned, in the current study, the mean of hemoglobin levels for IDA in male and female participants were $11.61 \pm 0.67 \mathrm{~g} / \mathrm{dl}$ and $11.22 \pm 0.70$ $\mathrm{g} / \mathrm{dL}$ with high statistically significant association $(\mathrm{p}<0.001)$ compared to non-anemic male $(14.51 \pm 1.71 \mathrm{~g} / \mathrm{dl})$ and nonanemic female $(13.82 \pm 1.37 \mathrm{~g} / \mathrm{dl})$. Similarly, the mean of Serum Ferritin, Serum Iron and TIBC for IDA male and female participants had high significantly differences average values compared to non-anemic male and female participants groups $(p<0.001)$. Females were more prone to be anemic than males, particularly at reproductive age, because of the influence of menstruation and socioeconomic customs. This finding of our study supports the observation of some previous studies [22], [23].

The sociodemographic risk factors of IDA in school adolescents were also evaluated, and we found significant associations of sex $[\mathrm{P}=0.001, \mathrm{OR}=0.39(0.22-0.69)]$, residence areas $[\mathrm{P}=0.001, \mathrm{OR}=3.30(1.55-7.02)]$ and school sites $[\mathrm{P}=0.002]$ with IDA respectively. Other factors such as age, knowledge on iron deficiency $(p=0.338)$ and family size $(\mathrm{P}=0.79)$ did not have any significant association with IDA. In our studies, we had one school site per village. In the western Cameroon region, eating habits varied from one village to another and this could explain the differences observed. In addition, several factors that are associated with pathophysiological mechanisms of iron deficiency coincide in adolescents to give rise to increased nutritional requirements, e.g., the adolescent physical activity and growth spurt. It has been demonstrated that, iron requirements vary a lot depending on the age, birth conditions and, of course, the weight, sex, and size of the child [24]. IDA was more represented in adolescents in urban area $(7.7 \%)$ than rural $(1 \%)$. This result disagrees with that of EDSC V 2018 where anemia was more represented in rural than urban [16].

In our study, females in the 10-12 age range had $18 \%$ prevalence of IDA against $16.67 \%$ for males in the same range. In this case, IDA were more represented in females than in males. This result was similar to that of Abdullah Ahmed among University Students in Hodeida Province, Yemen. In his study, the $54.00 \%$ of participant iron deficient anemic were females (82) and $46.0 \%$ were males (70) [1]. This difference could partly be explained by the increase in needs for adolescents more marked in girls due to menstruation. As the loss of $1 \mathrm{~mL}$ of blood corresponds to 0.5 $\mathrm{mg}$ of iron and the menstrual losses are on average 40 to 50 $\mathrm{mL}$, which can reach $80 \mathrm{~mL}$ in $10 \%$ of women, deficiency 
situations are possible. In adolescent girls, this deficiency situation is favored by insufficient consumption of meat, or even adherence to a lacto-vegetarian diet [11]-[26]. This idea is reinforced with an European study in adolescents showing that not only iron intakes are significantly lower in adolescent girls than in adolescent boys (11 mg versus $14 \mathrm{mg}$ / day), but the ratio of haem iron / non-haem iron intakes was not satisfactory, only in $27.6 \%$ of girls compared to $86.3 \%$ of boys [27].

In the other hand, severe troubles of eating behavior like anorexia and nervosa can explain why female adolescents were more anemic than male. In fact, the risk of nutritional deficiency more often concerns girls than boys who are looking for being tall, strong, and muscular. While teenage girls dread getting fat, frequently follow restrictive diets and often orientate these restrictions on nutritionally essential food groups, like dairy products, meat, fish and eggs [11].

Father's profession and menstruation periods are shown not to be protective factors for the occurrence of anemia in our participants. Family size and lack of knowledge could partially explain the high rate of anemia observed in this community among adolescents because iron deficiency decreased with the level of knowledge, as well as with the family size [28]. The reduction of the amount of adult food for the benefit of children $(26.7 \%)$ was used in big family size to cope with a lack of food that can expose adolescents to IDA [29].

Concerning dietary habit, in this study, we found that, consumption of vegetable [OR: $0.30(0.17-0.54)]$, fruits, [OR: $0.26(0.12-0.52)$ ] and fats [OR: $0.33(0.12-0.91)$ ] significantly decreases the risk of IDA $(p<0.05)$, whereas the consumption of legumes [OR: 2.60 (1.57 - 4.32)] significantly increased the risk of IDA.

Similarly, a significant association was found between IDA and meal consumption frequency: majority (70.4\%) of the participants had meal frequency of 1-2 times per day with IDA prevalence of $7.1 \%$ out of $8.7 \%$. This result suggests that IDA depends on meal consumption frequency per day. It could be explained by poverty that leads to food insecurity with less nutrient intakes. Because $10.2 \%$ of households in Cameroon are frequently used to coping strategies of food consumption such as eating less preferred food or cheaper food $(62.0 \%)$, reduction of the number of meals per day $(31.4$ \%) [29].

Furthermore, a significant association was found between IDA and Weak DDS (Diet Diversity Score), less than half (27 $\%$ ) of study participants had a medium DDS (DDS=6). Among participants with weak DDS $(<6)$, those with four food groups' consumption had the maximum percentage of IDA $(2.7 \%, n=21)$. This suggests that the diet was undiversified therefore, monotonous. These findings agree with the report of WHO 2008 about children. If children's diets are not diversified and if they are not fed with an appropriate frequency, they would be vulnerable to micronutrient deficiencies [16]. This result agrees with that of ENSAN, 2019 in Cameroon. It revealed that, almost a third $(32.4 \%)$ of households in Cameroon have an undiversified diet, made up with less than four groups of food daily [29]. In fact, the DDS corroborates with daily meal consumption frequency of our participants to explain the prevalence of IDA in this study. Fish-shrimp, vegetables, meat -poultry, dairy products and fruits which were less consumed were more protective of IDA than fats, cereals, drinks-saucespices-condiments, most often of vegetable origin and in ferric form $(\mathrm{Fe} 3+)$ that must be reduced to ferrous iron $(\mathrm{Fe} 2+)$ prior to its absorption that turns out much poorer $(<10 \%)$ [11]. Drinks-sauce-spices-condiments, roots-tubers, nutsseeds, eggs, and legumes were more consumed. Therefore, these diets mostly vegetarian were rich in non-haem iron and poor in haem iron. In fact, the regulation of iron status is based almost exclusively on intestinal absorption iron. This is based on tracks different from haem iron whose absorption is very efficient (25 to $35 \%$ ) and from non-haem iron. For instance, in cereals (wheat, corn, rice). This difference is likely to change when food is mixed. Phytates and phosphates in cereals inhibit iron absorption, while protein and vitamin $\mathrm{C}$ promote its absorption. The consumption of fresh fruits and vegetables, rich in vitamin $\mathrm{C}$, during a meal, would therefore facilitate the absorption of iron. Egg yolk, on the other hand, inhibits it, although the egg is one of the best sources of iron [30]. Vegetables and legumes including beans, peas, and lentils, are great sources of iron, but they contain tannins or polyphenols, which are iron absorption inhibitors. These findings agreed with that of ENSAN who reported that, West Cameroon is particularly concerned by the low consumption of iron rich foods (15.9\%). About $2.2 \%$ households could go seven days without consuming any iron-rich foods [29]. Additionally, our school's teenagers were not aware of foods and drinks that contain high amount of iron absorption inhibitors. Iron absorption inhibitors like phytates are found in bread, wheat bran, breakfast cereals, oats, and rice. Other iron absorption inhibitor like tannins or polyphenols are found in tea, coffee, cocoa, and certain vegetables while calcium is found in milk and cheese [31].

The observation of significant association of low consumption of vegetables/fruits, meat, fish, chicken $(p<0.001)$ with the occurrence of IDA was also reported by Abdullah Ahmed et al. among University Students in Hodeida Province in Yemen [1].

Undiversified and monotonous diet have been indicated in some studies in Mbouda, West Region of Cameroon, regarding young children and woman of reproductive age [15], [29], [32]. Therefore, it can be confirmed that despite the quantity and numerous foodstuffs produced in West Region of Cameroon, particularly in Mbouda, the population still suffers from the nutritional problems which seem not to be linked to lack of food, but to inappropriate uses of available food resources [32].

The presence of IDA found in this study could be explained by an inadequate DDS (undiversified) overly vegetarian, law meal consumption frequency, diet poor in meat and fish, increased iron requirements at teenagers age, and unawareness about iron deficiency, the residence zone, and the site (school).

The limitation of this study lies in the fact that, we did not obtain data about additional blood parameters such as blood count or serum levels of folate and vitamin B12, reticulocyte count, $\mathrm{C}$ reactive protein (CRP) test or Helicobacter $(\mathrm{H}$. pylori) which would have allowed us to distinguish between different causes of anemia. Moreover, data did not provide information on quantity used or assign weight to food groups based on nutritional value. Future studies should consider 
including this information in order to further characterized IDA in this population and identify appropriate treatment strategies.

\section{CONCLUSION}

IDA is prevalent and considered as moderate health problems among school teenagers studied in Mbouda, western Cameroon. Our findings showed the prevalence of IDA was $82.4 \%$ and $17.64 \%$ in participants aged $13-19$ years and 10-12 years respectively. Possible causes of the high prevalence rate of IDA among school teenager's population may be attributed to inadequate DDS (undiversified) overly vegetarian, law consumption or frequency of meal, diets poor in meat and fish, family size, increased iron requirements due to high growth rate, unawareness about iron deficiency, the residence zone, and the site (school). Further studies should be carried out in the Western Region of Cameroon in order to further characterize IDA risk factors in this population and identify appropriate treatment strategies.

\section{ACKNOWLEDGMENT}

The authors would like to thank participants for their support towards the successful completion of the study.

\section{FUNDING}

This research received no external funding.

\section{CONFLICT OF INTEREST}

Authors declare that they do not have any conflict of interest.

\section{REFERENCES}

[1] Al-Alimi AA, Bashanfer S, Morish MA. Prevalence of Iron Deficiency Anemia among University Students in Hodeida Province, Yemen. Anemia. 2018; 2018.

[2] McLean E, Cogswell M, Egli I, Wojdyla D, De Benoist B. Worldwide prevalence of anaemia, WHO Vitamin and Mineral Nutrition Information System, 1993-2005. Public Health Nutrition. 2009; 12: 444-54.

[3] OMS/FAO. Principaux repères de l'OMS sur la sécurité sanitaire des aliments n.d. [Internet] [cited 2021 June 20] Available from: https://www.who.int/fr/news-room/fact-sheets/detail/food-safety

[4] Al-Zabedi EM. Prevalence and Risk Factors of Iron Deficiency Anemia among Children in Yemen. American Journal of Health Research. 2014; 2: 319.

[5] LA NUTRITION DANS LE PAYS EN DÉVELOPPEMENT n.d. [Internet] [cited 2021 June 20] Available from : http://www.fao.org/3/w0073f/w0073f40.htm

[6] WHO | Daily iron supplementation in children and adolescents 5-12 years of age. WHO 2019.

[7] Stoltzfus RJ. Iron deficiency: Global prevalence and consequences. Food and Nutrition Bulletin. 2003; 24: S99-103.

[8] Kumari R, Bharti RK, Singh K, Sinha A, Kumar S, Saran A, et al. Prevalence of iron deficiency and iron deficiency anaemia in adolescent girls in a tertiary care hospital. Journal of Clinical and Diagnostic Research. 2017; 11: BC04-6.

[9] Lopez A, Cacoub P, Macdougall IC, Peyrin-Biroulet L. Iron deficiency anaemia. The Lancet. 2016; 387: 907-16.

[10] Elfaki N. Iron Deficiency Anemia and Associated Risk Factors among Teenagers in Najran, Saudi Arabia. International Journal of Medical Research \& Health Sciences. 2019; 8: 108-14.
[11] Christian P, Smith ER. Adolescent Undernutrition: Global Burden, Physiology, and Nutritional Risks. Annals of Nutrition and Metabolism. 2018; 72: 316-28.

[12] Shill KB, Karmakar P, Kibria MG, Das A, Rahman MA, Hossain MS, et al. Prevalence of iron-deficiency anaemia among university students in Noakhali Region, Bangladesh. Journal of Health, Population and Nutrition. 2014; 32: 103-10.

[13] Smith NJ, Rosello S. Iron deficiency in infancy and childhood. The American Journal of Clinical Nutrition. 1953; 1: 275-86.

[14] DHS. Cameroon Demographic and Health Survey. 2020: 739.

[15] Modestine M, Sop K, Mananga M. Risk factors of anemia among young children in rural Cameroon. International Journal of Current Microbiology and Applied Sciences. 2015; 4: 925-35.

[16] Cameroon - Enquête Démographique et de Santé 2018 n.d. [Internet] [cited 2021 June 20] Available from: https://microdata.worldbank.org/index.php/catalog/3717

[17] Vincent A, Grande F, Compaoré E, Amponsah Annor G, Addy P, Aburime L, et al. FAO/INFOODS Food Composition Table for Western Africa (2019) - Table de composition des aliments FAO/INFOODS pour l'Afrique de l'Ouest (2019). 2020.

[18] Iron StatuS of populations Assessing the Second edition Including Literature Reviews Centers for Disease Control and Prevention Division of Nutrition and Physical Activity International Micronutrient Malnutrition Prevention and Control Program Department of Nutrition for Health and Development ISBN 9789241596107 (electronic version) (NLM classification: WD 105). 2007.

[19] Concentrations en hémoglobine permettant de diagnostiquer l'anémie et d'en évaluer la sévérité n.d. [Internet] [cited 2021 June 20] Available from: https://www.who.int/vmnis/indicators/haemoglobin fr.pdf

[20] WHO. Iron Deficiency Anaemia Assessment, Prevention, and Control A guide for programme managers. n.d.

[21] Fuhrmann D, Knoll LJ, Blakemore SJ. Adolescence as a Sensitive Period of Brain Development. Trends in Cognitive Sciences. 2015; 19: 558-66.

[22] Gedefaw L, Tesfaye M, Yemane T, Adisu W, Asres Y. Anemia and iron deficiency among school adolescents: burden, severity, and determinant factors in southwest Ethiopia. Adolescent Health, Medicine and Therapeutics. 2015; 6: 189.

[23] Mansour D, Hofmann A, Gemzell-Danielsson K. A Review of Clinical Guidelines on the Management of Iron Deficiency and Iron-Deficiency Anemia in Women with Heavy Menstrual Bleeding. Advances in Therapy. 2021; 38: 201-25.

[24] Miller JL. Iron deficiency anemia: A common and curable disease. Cold Spring Harbor Perspectives in Medicine. 2013; 3.

[25] Anémie par carence martiale chez l'adolescente | Pas à Pas en Pédiatrie n.d. [Internet] [cited 2021 June 20] Available from: https://pap-pediatrie.fr/hematologie/anemie-par-carence-martialechez-ladolescente

[26] Contribution à l'étude de la prévalence de l'anémie chez les enfants préscolaires de la région de Kenitra, Maroc n.d. [Internet] [cited 2021 June 20] Available from: http://www.didac.ehu.es/antropo/19/191/ElHioui.htm

[27] République du Cameroun: Enquête Nationale sur la Sécurité Alimentaire et Nutritionnelle, Avril 2021 - Données de Septembre 2020 - Cameroon |ReliefWeb n.d. [Internet] [cited 2021 June 20] Available from: https://reliefweb.int/report/cameroon/r-publique-du-camerounenqu-te-nationale-sur-la-s-curit-alimentaire-et

[28] Yiannikourides A, Latunde-Dada G. A Short Review of Iron Metabolism and Pathophysiology of Iron Disorders. Medicines. 2019; 6: 85 .

[29] Collings R, Harvey LJ, Hooper L, Hurst R, Brown TJ, Ansett J, et al. The absorption of iron from whole diets: A systematic review. American Journal of Clinical Nutrition. 2013; 98: 65-81.

[30] Mananga M-J, Modestine Kana-Sop M, Policarpe Nolla N, Inocent Gouado G. Feeding Practices, Food and Nutrition Insecurity of infants and their Mothers in Bangang Rural Community, Cameroon. J Nutr Food Sci. 2014; 4: 264. 


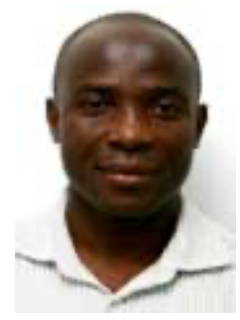

B. P. Telefo is a full professor at the department of Biochemistry, University of Dschang, Cameroon.

He was a Research assistant at the Laboratory of Nutrition, Toxicology \& Plant Studies and Medicinal products from the University of Yaoundé I (August 1996 - October 1998)> He did Post-Doctoral Research Internship at the Center of Andrology and Dermatology of Justus Liebig University, Giessen, Germany (October 2001 - April 2002) and University of Tours / Physiology of Reproduction and Behavior, Tours, France (October 2002 - November 2003). He studies Plants used in medicine, Analysis of the mechanisms by which some natural substances (obtained from medicinal plants) indirectly regulate ovarian activity by inducing or inhibiting the secretion and / or synthesis of $\mathrm{GnRH}$ and gonadotropins. He has published hundred articles in international peer review journals.

Prof. Telefo is a member of Cameroon bioscience society and many other international societies.

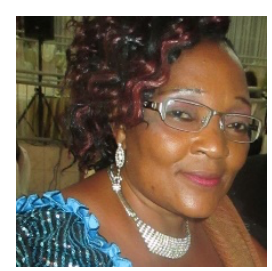

Professor M. M. Kana Sop is an Associate Professor in Biochemistry at the University of Douala, Cameroon. She holds a Master of Science in Biochemistry, a third cycle Doctorate from the University of Yaoundé $\mathrm{I}$, and a $\mathrm{PhD}$ in Biochemistry, specialized in Food Science and Nutrition from the University of Douala. Prof Modestine is a passionate teacher and researcher in Biochemistry with more than 20 years of experience in the study of feeding practices, nutrients intake, nutrition counselling, rehabilitation and malnutrition prevention and cure.

She has participated in more than 25 national and international conferences and seminars; she has successfully written and implemented more than three research projects with more than 25 publications in peerreviewed journals. She is involved in supervising students' and junior colleagues' research, as well as seminars, lectures, projects and scientific paper writing, Her personal research, Masters' and $\mathrm{PhD}$ students are mainly focused on: infant, young children feeding, food analyses and nutrient bioavailability and intakes from local foods. 